\title{
A STUDY TO ASSESS KNOWLEDGE ATTITUDE AND PRACTICES TOWARDS COVID-19 AMONG FRONTLINE WORKERS OF A NORTH INDIAN DISTRICT
}

\author{
Chintu Chaudhary ${ }^{1}$, Mohd Najmul Aqib Khan ${ }^{2}$, Sania Parveen ${ }^{3}$, Uma Sharma ${ }^{4}$, Veena Singh ${ }^{5}$, \\ Bhupinder Kaur Anand ${ }^{1}$ \\ ${ }^{1}$ Department of Community Medicine, Al-Falah School of Medical Sciences \& Research Center, Faridabad, \\ India \\ ${ }^{2}$ Department of Community Medicine, Government Medical College, Haldwani, Nainital, Uttarakhand, India \\ ${ }^{3}$ Department of Anesthesiology \& Critical Care, Jawaharlal Nehru Medical College, Aligarh, U.P, India \\ ${ }^{4}$ Dental Department, Civil Hospital, Palwal, Haryana, India \\ ${ }^{5}$ Department of Obstetrics \& Gynaecology, Al Falah School of Medical Sciences \& Research Center, Faridabad, \\ Haryana, India \\ Corresponding author: Dr. Mohd Najmul Aqib Khan \\ Email: drmnaqib@gmail.com, Phone (or Mobile) No.: +919045056591
}

\begin{abstract}
Frontline workers have been fighting hard since the novel coronavirus, also known as COVID-19, was declared a global pandemic by the WHO on March $12^{\text {th }}, 2020$. This study assessed the level of knowledge of frontline workers, attitudes of frontline workers, and how well the frontline workers of the area adapted to the ongoing epidemic. This study used a cross-sectional research design conducted among 440 frontline workers Palwal district in Haryana. Information regarding knowledge, attitude, practice, and socio-demographic characteristics was obtained using semi-coded and pretested questionnaire. Data were analysed using SPSS version 20. Independent t-test, ANOVA, Pearson's rank correlation test, and multivariate linear regression were used. A pvalue of $<0.05$ was considered significant. The mean of knowledge, attitude, and practice scores were 79.67 (SD $=1.81), 27.4(\mathrm{SD}=0.98)$, and $22.47(\mathrm{SD}=1.4)$, respectively. $94.8 \%$ of frontline workers had excellent knowledge, $68.6 \%$ had excellent attitude, and $57.7 \%$ had reasonable practice with significant positive correlation between the three. Knowledge score varied significantly with occupation $(p=0.003)$. Regression analysis showed that attitude score varied significantly with age, gender, and occupation $(\mathrm{p}<0.05)$. Practice score varied significantly with age ( $p<0.05)$. The majority of the HCWs had had excellent knowledge and attitude, but moderate practice towards COVID-19 with a significant positive correlation between them. Knowledge appeared to be significantly associated with profession; attitude with age, gender, occupation, source of information; and practice with age alone. Healthcare workers (HCWs) were using less authentic sources for information, which is an important aspect that needs immediate correction as ultimately it affects knowledge and can be reflected in attitude and practice.
\end{abstract}

Keywords: COVID-19, knowledge, attitude, practice, frontline workers

\section{INTRODUCTION}

The novel coronavirus (2019nCoV, formally known as SARS-CoV-2 or COVID-19) was first reported as a cluster of acute respiratory illness in Wuhan, Hubei Province, China, in December 2019, from where it spread briskly to more than 200 countries (Johns Hopkins Coronavirus Resource Center, 2020). Coronaviruses are a part of large family of viruses which may cause illness in animals or humans. Ranging from the common cold to more severe diseases such as Middle East Respiratory Syndrome (MERS) and Severe Acute Respiratory Syndrome (SARS), several coronaviruses evidently cause respiratory infections in humans. The outbreak of COVID-19 was announced in India on January 31, 2020 after detecting the first confirmed case which came from China and was diagnosed in Kerala. The virus strain, formerly labelled 2019-nCoV and the Wuhan coronavirus, was given a new taxonomic designation "severe acute respiratory syndrome coronavirus 2" (SARS-CoV-2) on February 11, 2020, and it became the official means to refer to the virus strain. On the same day, the WHO officially retitled the disease COVID-19 (Baig et al., 2020). It was declared a global 
pandemic by the WHO on March 12, 2020 (WHO, 2020)

India was not spared from the assault of COVID-19. India detected its first case on January 31, 2020 and took different measures to stop the spread of disease. Among them, most important were to educate people regarding the disease and importance of social distancing, hand hygiene, and respiratory hygiene to break the chain of the spread of infection. In India, where the informal sector caters approximately $80 \%$ of the workforce and about a third are employed as day-laborers, the lockdown policy may aggravate existing health and economic disparities. Implementing personal hygiene and public health behaviors, such as hand washing, social distancing, and use of face masks, are necessary to curb the spread of coronavirus, but it will be challenging to practice these in many cities and rural areas in developing settings (Dahab et al., 2020). Transmission may increase without sustained bans on large gatherings (including specific cultural and faith practices such as mass prayer gatherings, large weddings, and funerals), as these would act as super-spreading events. This situation may also be compounded by the spread of COVID-19 misinformation, including unsubstantiated treatments or promotion of futile preventive behaviors (Ioannidis, 2020)

Sensitivity analysis by Zhou et al. (2020) suggested enhancing the response rate of the media reporting the severity of COVID-19, as well as increasing the response rate of the public awareness to the media reports during the early phase of the COVID-19 outbreak could have significantly moved forward the peak time and reduced the peak size of the infection.

Compared with the general community, front-line healthcare workers (HWCs) were at increased risk for positive COVID-19 tests (Nguyen et al., 2020). Studies done in the country reported variable level of knowledge, attitude, and practice among $\mathrm{HCWs}$ with significant scope of improvement (Kandasamy et al.,
2020; Paul et al., 2020). Utilization of substantial knowledge, positive attitudes, and practices, hopefully, can help control the spread of COVID-19 (Puspitasari et al., 2020).

This study aimed to evaluate whether efforts and interventions to impart knowledge and awareness regarding preventive and control measure against COVID-19 were paying off. This included having knowledge about basic hygiene principles, modes of disease transmission, and social distancing. The level of knowledge, attitudes, and practices of frontline workers were assessed. This helped to identify difficulties and challenges faced by them in new circumstances and thus indicated the areas where further strengthening of activities was required, both in terms of quality and quantity. This study aimed to assess perception, attitude, and practices of frontline workers fighting COVID-19, either directly or indirectly in Haryana.

\section{METHODS}

This was a cross-sectional study conducted in Palwal, Haryana, among frontline workers who were involved in the management of the COVID-19 pandemic either directly or indirectly. As there was not much literature available at the time of study, it was assumed that half of the frontline workers (healthcare workers, security, and sanitary staff) were aware of COVID-19. Stratified random sampling with probability proportionate to size (PPS) was used to collect required samples. Assuming this prevalence with relative error of $5 \%$ at a significance level of $95 \%$, the sample size was calculated.

The equation used for calculating sample size is as follows:

$$
\mathrm{n}=\mathrm{Z}^{2} \mathrm{P}(1-\mathrm{P}) / \mathrm{e}^{2}
$$

Where,

- $\mathrm{Z}=$ level of confidence - 95\% (1.96)

- $\mathrm{P}=$ prevalence of awareness

- $\mathrm{e}=$ margin of error 
The sample size came out to be approximately 400. Assuming the nonresponse rate to be $10 \%, 440$ frontline workers were taken up for the study. The total frontline workers were divided in two strata. One consisted of workers directly involved in the management of COVID-19. The other consisted of security forces and sanitary workers who were indirectly helping in managing the pandemic. A pretested questionnaire-based survey was given by the investigators to the frontline workers, which included healthcare workers, security, and sanitary staff. Frontline workers were selected randomly for data collection and random numbers were taken from the list of participants for survey until the target sample size was achieved. A semi-coded and pretested questionnaire in the local language (Hindi) was used to collect the relevant information and to assess the level of knowledge and awareness regarding the preventive measures against COVID-19. Informed consent was taken from all the participants. The data collection was done over a period of one month in May 2020.

The inclusion criteria for collection of relevant information were only those frontline workers who were on duty and willing to participate were included in the study.

\section{Questionnaire}

WHO training material for the detection, prevention, response, and control of COVID-19 was used to develop a questionnaire for this study and subsequently pilot tested. For better understanding of the questions by the participants, required changes were made before the final survey and the questions were rearranged to ensure efficiency. A 67item survey instrument was finally developed using WHO course materials on emerging respiratory viruses, including COVID-19 (Supplementary Table 1) (WHO, 2020) This took approximately 10 minutes to fill out.
The knowledge section of the questionnaire consisted of 41 questions (Supplementary Table 1). Questions were either in the form of a multiple choice answer or in the form of true, false, or no opinion. Correct answers were worth two points, while incorrect answers were allocated one point. No points were given to a "no opinion" answer. Overall knowledge score ranged from 41 to 82 . Individuals scoring 66 and below were categorized as having poor knowledge, 67 to 78 as having moderate knowledge, and above 79 as excellent knowledge of COVID-19.

14 questions were asked (A1-A15, Supplementary Table 1) to evaluate the attitude towards COVID-19. Answering and scoring systems were very much similar to the first section (true $=3$, false $=$ 1 , and no opinion $=0$ ). The total attitude score ranged from 14 to 28 . A score of under 23,24 to 27 , and full 28 was classified as poor, moderate, and excellent attitude towards COVID-19, respectively.

Regarding practice and approach towards the disease, 12 questions were asked (Supplementary Table 1), with a similar scoring system as previous (correct $=3$, incorrect $=1$, no opinion $=0$ ). Total scores of under 12, 21 to 23, and full 24 were classified as poor, moderate, and excellent practice towards COVID-19, respectively.

\section{Statistical Analysis}

Statistical analyses were performed by using statistical package for social sciences (SPSS) version 20.0. Data were presented as mean \pm SD and proportions as appropriate. The independent t-test and ANOVA were used to compare mean. Pearson's rank correlation test was used to identify any correlation between knowledge, attitude, and practice. Multivariate linear regression analysis was done to determine the relation between variables and KAP. Unstandardized regression coefficients (95\%) were used for evaluating correlation among variables 
with KAP towards COVID-19. The statistical significance level was set at $p<$ 0.05 .

\section{RESULTS}

\section{Study Population Profile}

Table 1. Socio-demographic profile of study participants

\begin{tabular}{|c|c|c|}
\hline Variable & $\begin{array}{l}\text { Number } \\
\text { (N) }\end{array}$ & $\begin{array}{l}\text { Percent } \\
(\%)\end{array}$ \\
\hline \multicolumn{3}{|l|}{ Age group } \\
\hline $18-30$ & 229 & 52.0 \\
\hline $31-40$ & 133 & 30.2 \\
\hline $41-50$ & 51 & 11.6 \\
\hline $51-60$ & 27 & 6.1 \\
\hline \multicolumn{3}{|l|}{ Sex } \\
\hline Male & 197 & 44.8 \\
\hline Female & 243 & 55.2 \\
\hline \multicolumn{3}{|l|}{ Residence } \\
\hline Rural & 279 & 63.4 \\
\hline Urban & 161 & 36.6 \\
\hline \multicolumn{3}{|l|}{ Education } \\
\hline Primary & 80 & 18.2 \\
\hline High school & 92 & 20.9 \\
\hline Intermediate & 102 & 23.2 \\
\hline $\begin{array}{l}\text { Graduate and } \\
\text { above }\end{array}$ & 166 & 37.7 \\
\hline \multicolumn{3}{|l|}{ Occupation } \\
\hline Police & 43 & 9.8 \\
\hline Nurses & 98 & 22.3 \\
\hline A.N.M & 69 & 15.7 \\
\hline Asha & 150 & 34.1 \\
\hline Sanitary worker & 80 & 18.2 \\
\hline \multicolumn{3}{|c|}{ Information source } \\
\hline TV & 366 & 83.2 \\
\hline Internet & 44 & 10.0 \\
\hline Radio & 24 & 5.5 \\
\hline $\begin{array}{l}\text { WhatsApp/social } \\
\text { media }\end{array}$ & 6 & 1.4 \\
\hline \multicolumn{3}{|c|}{ Most effective source of information } \\
\hline TV & 391 & 88.9 \\
\hline Internet & 49 & 11.1 \\
\hline Total & 440 & 100 \\
\hline
\end{tabular}

Mean age of the study participants came out to be $33.10 \pm 9.20$ years with more than $80 \%$ of the individuals being under 40 years of age. The majority of participants were females and received an education of up to graduate school and above. $34.1 \%$ of the study participants were ASHA workers. The majority of frontline healthcare workers were getting information regarding COVID-19 from television and believed it to be the most effective source for information.

\section{Knowledge, Attitude, and Practice Correlation}

Mean scores of the included 440 frontline workers are shown in Figure 1. In this study, significant positive correlation was reported between the mean of knowledge, attitude, and practice scores. Positive correlation was found in knowledge vs attitude $(\mathrm{r}=0.50: \mathrm{p}<0.001)$, knowledge vs practice ( $\mathrm{r}=0.21: \mathrm{p}<0.001)$, and attitude vs practice $(\mathrm{r}=0.09: \mathrm{p}=$ $0.041)$.

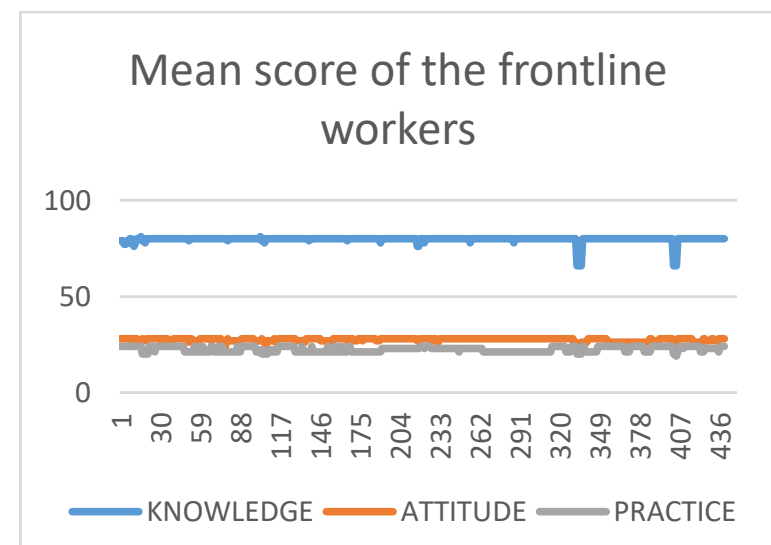

Figure 1. Line diagram of knowledge, attitude, and practice of frontline workers $(\mathrm{N}=440)$

\section{Knowledge of COVID-19}

Based on these results, the majority of the frontline workers had excellent knowledge about the disease $(94.8 \%)$. The mean knowledge score was 79.67(SD = 1.81, range 41-82; Table 2). Except for the occupation ( $\mathrm{p}=0.003)$, knowledge scores in this study did not vary considerably among age groups, gender, residence, education level, and source of information for the individuals (Table 3 ). 
All the HCWs enrolled in the study knew the causative agent of the disease. Except for diarrhea, almost all of the HCWs were aware about the symptoms of the concerned disease as only about $4 \%$ considered diarrhea as a symptom. Same is the case is with knowledge about nature of the disease in terms of its fatality, percentage of symptomatic cases, and cases which require ICU care. All HCWs knew about the transmission routes, $97.3 \%$ knew there is no definitive treatment at present, and $98.6 \%$ selected the correct incubation period. Almost all or HCWs had knowledge about the susceptible groups for the disease, but $100 \%$ were sure that the disease is more dangerous for pregnant females. Preventive measures like frequent hand washing, use of sanitizer, coughing, sneezing, spitting etiquette, avoiding mass gatherings, and when to consult a medical practitioner were known to all. Knowledge about who should wear a mask to reduce transmission of COVID-19 was also very well imparted to HCWs as a result of frequent training and meetings during this pandemic. Most were familiar with the quarantine and isolation period required and almost all were well versed with the the criteria and eligibility of an individual to get tested for COVID-19 (Supplementary Table).

\section{Attitude Towards COVID-19}

Most or all HCWs in the study firmly believed, in accordance with the established facts, the non-availability of a vaccine for the disease at present, severity of the disease, transmission through domestic animals, role of early detection for improved outcome, role of health education, and taking necessary precautions in prevention and the presence of a cure for COVID-19. However, $38.2 \%$ of HCWs also believed that disease is $100 \%$ fatal. More than $98 \%$ had the attitude that authorities should restrict travel to and from COVID-19 disease areas and should be ready to continue educational centers closure, while $100 \%$ agreed with restricted access to religious sitesand quarantine/isolation COVID-19 patients in special hospitals, and $96.1 \%$ supported the city lockdown move (Supplementary Table).

The mean correct answer score of the 14 questions regarding attitude towards COVID-19 was 27.4 (SD $=0.98$, range 1428). The majority of the participants $(68.6 \%)$ had excellent attitude towards COVID-19. Attitude scores significantly varied across age groups, genders, education levels, occupations, and source of information for the individuals (Table 3). Multiple linear regression analysis showed that young age, female gender, occupation (nurse, ANM, ASHA) were significantly associated with having better attitude towards COVID-19 $(\mathrm{p}<0.05)$ (Table 4).

\section{Practice Towards COVID-19}

Based on the results, the average correct answer score of the 12 questions regarding COVID-19 practice was 22.47 $(\mathrm{SD}=1.4$, range $12-24)$. The majority of participants $(57.7 \%)$ had reasonable practice towards COVID-19 (Table 2). All the participants were taking extra precautions, practicing hand hygiene, consuming home-cooked food, and almost all were regularly exercising, while $94.8 \%$ were avoiding going out unnecessarily. $40.2 \%$ were working from home intermittently if required. Since a large section of these workers could not afford to have their own means of transport, only $39.5 \%$ were able to avoid public transportation. Just over a quarter of the total HCWs were using herbal products and Ayurvedic medicine for prevention, but $100 \%$ were taking vitamin supplements for the same purpose. As far as one of the most important preventive practice of wearing the mask is concerned, $84.8 \%$ reported wearing it all the time, $8.4 \%$ wearing it in public places only, and $6.8 \%$ answered wearing it most of the time (Supplementary Table).

Practice scores significantly varied across age groups, education levels, occupations, and sources of information for 
the individuals (Table 3). Multiple linear regression analysis showed that only age was significantly associated with practice, i.e., individuals in the age group 41-50 had significantly better practice compared to individuals in other age groups (Table 4).

Table 2. Level and mean score of knowledge, attitude, practice

\begin{tabular}{lcccccc}
\hline Variables & $\begin{array}{c}\text { Number } \\
\text { of } \\
\text { Questions }\end{array}$ & $\begin{array}{c}\text { Range of } \\
\text { Score }\end{array}$ & $\begin{array}{c}\text { Total score } \\
(\text { Mean } \pm \text { SD) }\end{array}$ & \multicolumn{3}{c}{ Level (\%), N = 440 } \\
\cline { 5 - 7 } Knowledge & 41 & $41-82$ & $79.67 \pm 1.81$ & 1.6 & 3.6 & 94.8 \\
\hline Attitude & 14 & $14-28$ & $27.46 \pm 0.98$ & 2.0 & 29.3 & 68.6 \\
\hline Practice & 12 & $12-24$ & $22.47 \pm 1.42$ & 3.4 & 57.7 & 38.9 \\
\hline
\end{tabular}

Table 3. Socio-demographic association of knowledge, attitude and practice

\begin{tabular}{|c|c|c|c|c|}
\hline \multirow[t]{2}{*}{ Variable } & \multicolumn{3}{|c|}{ Mean Score \pm SD } & \multirow[t]{2}{*}{ P-value } \\
\hline & & \\
\hline $18-30$ & $79.83 \pm 1.05$ & $27.57 \pm 0.77$ & $22.40 \pm 1.39$ & $\mathrm{~K}(0.20, \mathrm{~W})$ \\
\hline $31-40$ & $79.61 \pm 2.10$ & $27.49 \pm 0.98$ & $22.29 \pm 1.38$ & $\mathbf{A}\left(0.037, \mathbf{W}^{*}\right)$ \\
\hline $41-50$ & $79.00 \pm 3.35$ & $27.03 \pm 1.50$ & $22.96 \pm 1.50$ & $\mathbf{P}(\mathbf{0 . 0 0 6 )}$ \\
\hline $51-60$ & $79.88 \pm 0.57$ & $27.14 \pm 1.16$ & $23.00 \pm 1.35$ & \\
\hline \multicolumn{5}{|l|}{ Sex } \\
\hline Male & $79.53 \pm 2.23$ & $27.18 \pm 1.23$ & $22.55 \pm 1.52$ & $\begin{array}{l}\mathrm{K}(0.17) \\
\mathrm{A}(<\mathbf{0 . 0 0 1})\end{array}$ \\
\hline Female & $79.78 \pm 1.37$ & $27.68 \pm 0.64$ & $22.40 \pm 1.32$ & $\mathrm{P}(0.262)$ \\
\hline \multicolumn{5}{|l|}{ Residence } \\
\hline Rural & $79.78 \pm 1.49$ & $27.40 \pm 0.94$ & $22.45 \pm 1.47$ & $\begin{array}{l}\mathrm{K}(1.46) \\
\mathrm{A}(0.115)\end{array}$ \\
\hline Urban & $79.49 \pm 2.25$ & $27.55 \pm 1.04$ & $22.49 \pm 1.32$ & $\mathrm{P}(0.781)$ \\
\hline \multicolumn{5}{|l|}{ Education } \\
\hline Primary & $79.76 \pm 1.59$ & $27.22 \pm 1.12$ & $22.22 \pm 1.51$ & $\mathrm{~K}(0.762)$ \\
\hline High school & $79.52 \pm 2.50$ & $27.25 \pm 1.15$ & $22.23 \pm 1.55$ & $A\left(0.005, W^{*}\right)$ \\
\hline Intermediate & $79.77 \pm 0.71$ & $27.61 \pm 0.74$ & $22.98 \pm 1.33$ & $\mathbf{P}\left(<0.001, \mathbf{W}^{*}\right)$ \\
\hline $\begin{array}{l}\text { Graduate and } \\
\text { above }\end{array}$ & $79.65 \pm 1.93$ & $27.59 \pm 0.90$ & $22.40 \pm 1.27$ & \\
\hline \multicolumn{5}{|l|}{ Occupation } \\
\hline Police & $79.02 \pm 3.60$ & $27.11 \pm 1.38$ & $23.06 \pm 1.35$ & $\mathrm{~K}\left(\mathbf{0 . 0 0 3}, \mathrm{W}^{*}\right)$ \\
\hline Nurses & $79.91 \pm 0.56$ & $27.92 \pm 0.32$ & $22.11 \pm 1.15$ & $\mathrm{~A}\left(<0.001, \mathrm{~W}^{*}\right)$ \\
\hline A.N.M & $79.56 \pm 0.94$ & $27.73 \pm 0.72$ & $23.21 \pm 1.04$ & $\mathbf{P}\left(<0.001, \mathrm{~W}^{*}\right)$ \\
\hline Asha & $79.95 \pm 0.29$ & $27.48 \pm 0.88$ & $21.94 \pm 1.41$ & \\
\hline Sanitary worker & $79.30 \pm 3.07$ & $26.80 \pm 1.12$ & $22.93 \pm 1.51$ & \\
\hline \multicolumn{5}{|c|}{ Information source } \\
\hline TV & $79.80 \pm 1.33$ & $27.54 \pm 0.88$ & $22.39 \pm 1.39$ & $\mathrm{~K}\left(0.121, \mathrm{~W}^{*}\right)$ \\
\hline Internet & $78.95 \pm 3.59$ & $27.06 \pm 1.40$ & $23.09 \pm 1.34$ & $\mathrm{~A}\left(\mathbf{0 . 0 2 3}, \mathrm{W}^{*}\right)$ \\
\hline Radio & $79.91 \pm 0.40$ & $27.00 \pm 0.83$ & $22.50 \pm 1.53$ & $\mathrm{P}\left(0.042, \mathrm{~W}^{*}\right)$ \\
\hline $\begin{array}{l}\text { WhatsApp/social } \\
\text { media }\end{array}$ & $76.16 \pm 5.07$ & $27.16 \pm 0.98$ & $22.66 \pm 2.06$ & \\
\hline
\end{tabular}

*Welch's annova 
Table 4. Multivariate linear regression of association between demographic characteristics with attitude and practice scores of COVID-19

\begin{tabular}{|c|c|c|c|}
\hline \multicolumn{4}{|l|}{ Attitude } \\
\hline Variables & $\begin{array}{l}\text { Unstandardized } \\
\text { Coefficients }\end{array}$ & P-value & VIF* $^{*}$ \\
\hline Age group & $\begin{array}{c}-0.118 \\
(-0.219 \text { to }-0.017)\end{array}$ & 0.022 & 1.069 \\
\hline Sex & $\begin{array}{c}0.387 \\
(0.202 \text { to } 0.572) \\
\end{array}$ & $<0.001$ & 1.113 \\
\hline Education & $\begin{array}{c}0.014 \\
(-0.88 \text { to } 0.117)\end{array}$ & 0.785 & 1.761 \\
\hline Occupation & $\begin{array}{c}-0.117 \\
(-0.197 \text { to }-0.038)\end{array}$ & 0.004 & 1.769 \\
\hline $\begin{array}{l}\text { Source } \\
\text { information }\end{array}$ & $\begin{array}{c}-0.209 \\
(-0.369 \text { to }-0.059)\end{array}$ & 0.007 & 1.125 \\
\hline \multicolumn{4}{|l|}{ Practice } \\
\hline Age group & $\begin{array}{c}0.190 \\
(0.039 \text { to } 0.341)\end{array}$ & 0.014 & 1.048 \\
\hline Education & $\begin{array}{c}0.122 \\
(-0.032 \text { to } 0.276)\end{array}$ & 0.120 & 1.731 \\
\hline Occupation & $\begin{array}{c}0.025 \\
(-0.095 \text { to } 0.145)\end{array}$ & 0.683 & 1.767 \\
\hline $\begin{array}{l}\text { Source of } \\
\text { information }\end{array}$ & $\begin{array}{c}0.148 \\
(-0.074 \text { to } 0.370)\end{array}$ & 0.191 & 1.073 \\
\hline
\end{tabular}

Table 5. Supplementary table

\section{Knowledge}

Correct

Response

$(\%)$

1. The causative agent of COVID-19

2. Is high fever a symptom of COVID-19

3. Is dry cough a symptom of COVID-19

4. Is sore throat a symptom of COVID-19

5. Is body ache a symptom of COVID-19

6. Is diarrhoea a symptom of COVID-19

7. Is difficulty in breathing symptom of COVID-19

8. It is a highly fatal disease

9. In $80 \%$ of the cases it is mild

10. ICU care is needed in $5 \%$ of patients only

11. COVID-19 spreads through air droplets by cough or sneeze of an infected person

12. COVID-19 spreads through personal contact with an infected person (100) Yes

13. COVID-19 spread through by touching contaminated objects used by an infected person

14. COVID-19 spread through community gathering

15. Can COVID-19 patients spread the disease without having fever $\&$ cough
(100) Virus

(100) Yes

(100) Yes

(99.1) Yes

(99.1) Yes

(3.9) Yes

(100) Yes

(99.3) Yes

(96.6) Yes

(100) Yes

(100) Yes

(100) Yes

(100) Yes

(100) Yes 


\section{Knowledge}

\section{Correct}

Response

(\%)

\begin{tabular}{|c|c|}
\hline 16. Incubation period for COVID-19 & $\begin{array}{l}\text { (98.6) 3-14 } \\
\text { days }\end{array}$ \\
\hline 17. Definitive treatment for COVID-19 is present & $(97.3) \mathrm{No}$ \\
\hline \multirow{2}{*}{ 18. In which age group is the disease more dangerous } & $(98.6)$ \\
\hline & Elderly \\
\hline 19. Disease is more dangerous in pregnant women & $(0.0)$ No \\
\hline 20. Disease is more dangerous in people with weakened immune systems & (99.5) Yes \\
\hline 21. Is COVID-19 more dangerous for older individuals & (99.5) Yes \\
\hline $\begin{array}{l}\text { 22. Disease is more dangerous in people with cancer, diabetes, and } \\
\text { chronic respiratory diseases }\end{array}$ & (100) Yes \\
\hline $\begin{array}{l}\text { 23. The death rate is high in elderly and patients with other chronic } \\
\text { diseases }\end{array}$ & (100) Yes \\
\hline 24. Wash your hands with soap and water regularly & (100) Yes \\
\hline 25. Use hand sanitizer with at least $70 \%$ alcohol & (100) Yes \\
\hline $\begin{array}{l}\text { 26. Cover your nose and mouth with handkerchief /tissue while sneezing } \\
\text { \& coughing }\end{array}$ & (100) Yes \\
\hline 27. Avoid mass gatherings and crowded places & (100) Yes \\
\hline 28. Avoid spitting in public areas & (100) Yes \\
\hline 29. Consult a doctor immediately if symptoms appear & (100) Yes \\
\hline 30. Common people should wear a mask to reduce spread of COVID-19 & (97.3) Yes \\
\hline $\begin{array}{l}\text { 31. Healthcare workers should wear a mask to reduce spread of COVID- } \\
19\end{array}$ & (100) Yes \\
\hline $\begin{array}{l}\text { 32. Persons having cough and cold should wear a mask to reduce spread } \\
\text { of COVID-19 }\end{array}$ & (100) Yes \\
\hline $\begin{array}{l}\text { 33. COVID-19 patients should wear a mask to reduce spread of COVID- } \\
19\end{array}$ & (100) Yes \\
\hline $\begin{array}{l}\text { 34. Caregivers to COVID-19 patients/suspects should wear a mask to } \\
\text { reduce spread of COVID-19 }\end{array}$ & (100) Yes \\
\hline $\begin{array}{l}\text { 35. Children and adolescents girls should take extra precautions for } \\
\text { COVID-19 prevention }\end{array}$ & (100) Yes \\
\hline $\begin{array}{l}\text { 36. Q \& I isolating COVID-19 patient can reduce the spread of the } \\
\text { disease }\end{array}$ & (99.8) Yes \\
\hline 37. Is 14 days isolation required for COVID-19 patient & $(100)$ Yes \\
\hline 38. Common people should be tested for COVID-19 & (97.0) Yes \\
\hline 39. Contacts should be tested for COVID-19 & (100) Yes \\
\hline $\begin{array}{l}\text { 40. People with history of international travel within } 14 \text { days should be } \\
\text { tested for COVID-19 }\end{array}$ & (100) Yes \\
\hline 41. Healthcare workers should be tested for COVID-19 & (100) Yes \\
\hline Attitude & $\begin{array}{l}\text { Correct } \\
\text { Response }\end{array}$ \\
\hline 42. Is there any vaccine for COVID-19 & $(98.2) \mathrm{No}$ \\
\hline 43. Do all the COVID-19 affected patients die & $(61.8) \mathrm{No}$ \\
\hline 44. Can domestic animals transmit it to humans & $(98.0)$ No \\
\hline 45. Early detection of COVID-19 can improve treatment and outcome & (100) Yes \\
\hline 46. Health education can help prevent COVID-19 & (100) Yes \\
\hline
\end{tabular}




\section{Knowledge}

Correct

Response

(\%)

47. Is COVID-19 a severe disease

48. Taking precautions can prevent COVID-19

(100) Yes

(99.5) Yes

49. Is there a cure for COVID-19

(100) No

50. Is there awareness in the community for COVID-19

(97.0) Yes

51. Authorities should restrict travel to and from COVID-19 disease areas to prevent contamination

52. Authorities should quarantine COVID-19 patients in special hospitals (100) Yes

53. In the event of an increase in the number of cases of COVID-19, authorities should be ready to close educational centers

(98.4) Yes (kindergartens, schools, and universities).

54. Restricted access by the authorities to religious sites, shrines, and mosques is right

55. Lockdown and quarantine in the city was the right move amid rising cases of COVID-19

\section{Practice}

(100) Yes

(96.1) Yes

Correct Response

56. In order to prevent contracting and spreading COVID-19, I avoid going out of my home unnecessarily

(94.8) Yes

57. In order to prevent contracting and spreading COVID-19, I do regular exercise

(98.2) Yes

58. In order to prevent contracting and spreading COVID-19, I avoid consuming outdoor food

59. In order to prevent contracting and spreading COVID-19, I avoid handshaking

60. In order to prevent contracting and spreading COVID-19, I avoid public transportation

61. In order to prevent contracting and spreading COVID-19, I do work from home if needed

62. In order to prevent contracting and spreading COVID-19, I frequently wash my hands

63. Do you take extra precautions to prevent contracting COVID-19

64. In order to prevent contracting and spreading COVID-19, I use disinfectant and practice hand hygiene

65 . Herbal products and ayurvedic medicine are used to prevent contracting COVID-19

66. In order to prevent contracting COVID-19, I take vitamin supplements

67. In order to prevent contracting and spreading COVID-19, when do you use facial masks
(100) Yes

(100) Yes

(39.5) Yes

(40.2) Yes

(100) Yes

(100) Yes

(26.0) Yes

(6.8) Most

of the time
(100) Yes

(100) Yes

\section{DISCUSSION}

To the best of the authors' knowledge, this study is among the few initial studies investigating the KAP towards COVID-19 amongst frontline workers in India.

In this study, significant positive correlation was reported between the mean knowledge, attitude, and practice scores. 
Knowledge vs attitude indicates having more knowledge about the disease will lead to adoption of better attitude and practice. Also, better attitude will push the frontline workers towards adoption of good practices (Hagger and Hagger, 2019) Similar correlations between the three was reported in the other KAP study in a neighbouring country (Saqlain et al., 2020). However other researchers did show a significant negative correlation between knowledge scores and attitude score (Huynh et al., 2020).

In this study, $83.2 \%$ of the frontline healthcare workers received information regarding COVID-19 from television and $88.9 \%$ believe it to be the most effective source for the information (Table 1). This is contrary to other studies where the majority used social media as their main source of information, followed by other sources like radio, television, seniors/other colleagues (Huynh et al., 2020; Saqlain et al., 2020; Srikanth Bhagavathula et al., 2020). This is important as in this global pandemic, that HCWs should consult reliable sources such as the WHO and US-CDC for guidelines and reports to lower concerns of xenophobia in the world, as there is also a pandemic of misinformation related to COVID-19 (Srikanth Bhagavathula et al., 2020). In this study, the majority (94.8\%) of frontline workers had excellent knowledge of the disease. The current finding among HCWs is in agreement with the findings of Saqlain et al. (2020) and Huynh et al. (2020) who reported that $93.2 \%$ and $88.4 \%$ participants, had sufficient knowledge regarding COVID-19. In other studies as well, the majority of the HCWs had sufficient knowledge about COVID-19 (Olum et al., 2020). In a study conducted by Olum et al. (2020) $69 \%$ of HCW had sufficient knowledge about COVID-19 (Huynh et al., 2020). In contrast, studies reported that only $69 \%$ and $56.5 \%$ of respondents had sufficient knowledge regarding transmission, symptoms, and treatment of COVID-19 (Huynh et al.,
2020; Nemati, Ebrahimi, and Nemati, 2020).

A mean knowledge score of more than 95 $\%$ (i.e. $79.67 \pm 1.81$ ) was reported for HCWs. A lower but comparable mean score of $82.4 \%$ and $81.7 \%$, indicating good knowledge, was reported by Olum (Olum et al., 2020) and Huynh (2020) respectively. Contrary, a survey by Bhagavathula et al. on COVID-19 (Srikanth Bhagavathula et $a l ., 2020)$ baseline studies among nurses in Gabon on Ebola (Rehman, Ghani, and Rehman, 2020) and HCWs in Ethiopia on Ebola, (Abebe et al., 2016) all reported poor knowledge. However, studies among the general population in China and U.S also came up with good knowledge scores of $90 \%$ and $80 \%$, respectively (Clements, 2020; Zhong et al., 2020). Except for the occupation ( $p=0.003)$, knowledge scores in this study did not vary considerably with age group, gender, residence, education level, and source of information for the individuals (Table 3). Other studies revealed association of having more knowledge with different demographic characteristics like occupation as pharmacist (Saqlain et al., 2020), young age of $<40$ years and getting information from media such as television. (Olum et al., 2020) However, a study in general population in Iran reported significantly lower knowledge among news media users, males, non-healthcare related professions and single participants (Moorthy et al., 2020).

Majority of the participants $(68.6 \%)$ had excellent attitude towards COVID-19 prevention. The mean score of the 14 attitude related questions to COVID-19 prevention came out to be more than $95 \%$ (i.e., $27.4 \pm 0.98$ ). The attitude score is in accordance with the knowledge scores, reported earlier in this study, as more knowledge is always useful towards developing better attitude. This is also evident by the positive correlation this study came up with between knowledge and attitude. Huynh et al. (2020) observed 93.3\% workers had sufficient attitude, 
which is in accordance to this study as well. Saqlain et al (2020) also showed highly positive attitude among HCWs towards COVID-19 with a positive linear correlation found between knowledge and attitude in their study (Saqlain et al., 2020). In line with this, Huynh et al. (2020) and Bhagavathula et al. (2020) also reported that the majority of HCWs have had a positive attitude towards COVID-19. Regression analysis in this study showed that young age, female gender, and occupation (nurse, ANM, ASHA) were significantly associated with having better attitude towards COVID-19 (Table 4). Another study also did not find any significant difference of attitude $(p>0.05)$ with age, gender, experience or profession/study (Saqlain et al., 2020). However, general population survey by Moorthy et al., (2020).did find that age, male gender, having lower level of education, being single, and having a higher number of household were significantly associated with having lower attitude towards COVID-19 ( $\mathrm{p}<0.01)$.

The average score in this study for the 12 questions regarding COVID-19 practice was $22.4 \pm 1.4$. The majority of participants $(57.7 \%)$ had moderate practice towards COVID-19 (Table 2). More than our study, good practice was reported among $88.7 \%$ HCWs in terms of following precautions to avoid COVID- 19 (Saqlain $e t$ al., 2020). Good COVID-19 prevention practices by HCWs have been reported in other studies by Olum et al. (2020) on COVID-19, Alfahan et al. (2016) on coronaviruses, Raab et al. on ebola virus disease in guinea (Raab et al., 2020) and in the general population of the Chinese on COVID-19 (Zhong et al., 2020). Regression analysis in the present study showed that only age (41-50) was significantly associated with better practice (Table 4). Other researchers found association of good practice with the profession of the HCWs (Saqlain et al., 2020), and of poor practice with age, male gender, being single, having healthcare- related occupations, and lower level of education among the general population (Moorthy et al., 2020).

\section{CONCLUSION}

This study had its limitations as well, especially in inferring the results because of the novelty of COVID-19 and limited studies were available to compare; therefore, it was difficult to generalize results across the general population. For appropriate interventions at national level, the knowledge and attitude of HCWs have to be assessed on a larger scale. The majority of the HCWs had had excellent knowledge, attitude, but moderate practice towards COVID-19 with a significant positive correlation between the three. Knowledge appeared to be significantly associated with profession; attitude with age, gender, occupation, and source of information; and practice with age alone. The findings also demonstrated that many HCWs were using less authentic sources for information: an important aspect that needs immediate consideration as ultimately it affects knowledge and can be reflected in attitude and practice. As a recommendation to the government agencies, that comprehensive training programme, targeting all HCWs, should be further pushed to promote all protective and preventive measures of COVID-19, to achieve steadiness in terms of clinical knowledge, attitude, and practice about COVID-19.

\section{REFERENCES}

Abebe, T. B. et al. (2016) 'Healthcare professionals' awareness, knowledge, attitudes, perceptions and beliefs about Ebola at Gondar University Hospital, Northwest Ethiopia: A cross-sectional study', Journal of Public Health in Africa, 7(2). doi: 10.4081/jphia.2016.570.

Alfahan, A. et al. (2016) 'In the era of corona virus: health care 
professionals' knowledge, attitudes, and practice of hand hygiene in Saudi primary care centers: a crosssectional study', Journal of Community Hospital Internal Medicine Perspectives, 6(4), p. 32151. doi: 10.3402/jchimp.v6.32151.

Baig, A. M. et al. (2020) 'Evidence of the COVID-19 Virus Targeting the CNS: Tissue Distribution, HostVirus Interaction, and Proposed Neurotropic Mechanisms', ACS Chemical Neuroscience. American Chemical Society, pp. 995-998. doi:

10.1021/acschemneuro.0c00122.

Clements, J. (2020) 'Knowledge and behaviors toward COVID-19 among U.S. residents during the early days of the pandemic', medRxiv, p. 2020.03.31.20048967. doi: 10.1101/2020.03.31.20048967.

Dahab, M. et al. (2020) 'COVID-19 control in low-income settings and displaced populations: what can realistically be done?', Conflict and Health, 14(1). doi: 10.1186/s13031020-00296-8.

'Emerging respiratory viruses, including COVID-19: methods for detection, prevention, response and control' (2020).

Hagger, M. S. and Hagger, M. S. (2019) 'The Reasoned Action Approach and the Theories of Reasoned Action and Planned Behavior', in Psychology. Oxford University Press. doi: 10.1093/obo/97801998283400240.

Huynh, G. et al. (2020) 'Knowledge and attitude toward COVID-19 among healthcare workers at District 2 Hospital, Ho Chi Minh City', Asian Pacific Journal of Tropical Medicine, 13(6), pp. 260-265. doi: 10.4103/1995-7645.280396.

Ioannidis, J. P. A. (2020) 'Coronavirus disease 2019: The harms of exaggerated information and nonevidence-based measures', European Journal of Clinical Investigation, 50(4). doi: 10.1111/eci.13222.

Johns Hopkins Coronavirus Resource Center. Date: 14.08.2020 (2020).

Kandasamy, S. et al. (2020) 'Knowledge, attitude and practices associated with COVID-19 among health care workers: A cross-sectional study in India.' doi: 10.21203/rs.3.rs87442/v1.

Man Fatally Poisons Himself While SelfMedicating for Coronavirus, Doctor Says - The New York Times (2020).

Moorthy, V. et al. (2020) 'Data sharing for novel coronavirus (COVID-19)', Bulletin of the World Health Organization, p. 150. doi: 10.2471/BLT.20.251561.

Nemati, M., Ebrahimi, B. and Nemati, F. (2020) 'Assessment of iranian nurses' knowledge and anxiety toward covid-19 during the current outbreak in iran', Archives of Clinical Infectious Diseases, 15(COVID-19). doi: 10.5812/archcid.102848.

Nguyen, L. H. et al. (2020) 'Articles Risk of COVID-19 among front-line health-care workers and the general community: a prospective cohort study'. doi: 10.1016/S24682667(20)30164-X.

Olum, R. et al. (2020) 'Coronavirus Disease-2019: Knowledge, Attitude, and Practices of Health Care Workers at Makerere University Teaching Hospitals, Uganda', Frontiers in Public Health, 8, p. 181. doi: 10.3389/fpubh.2020.00181.

Paul, G. et al. (2020) 'Assessment of knowledge gaps and perceptions about COVID-19 among health care workers and general public-national cross-sectional study', Journal of Anaesthesiology

Clinical 
Pharmacology, 0(0), p. 0. doi: 10.4103/joacp.joacp_326_20.

Puspitasari, I. M. et al. (2020) 'Knowledge, Attitude, and Practice During the COVID-19 Pandemic: A Review', Journal of Multidisciplinary Healthcare, Volume 13, pp. 727733. doi: 10.2147/JMDH.S265527.

Raab, M. et al. (2020) 'Knowledge, attitudes and practices towards viral haemorrhagic fevers amongst healthcare workers in urban and rural public healthcare facilities in the N'zérékoré prefecture, Guinea: A cross-sectional study', $B M C$ Public Health, 20(1), p. 296. doi: 10.1186/s12889-020-8433-2.

Rehman, H., Ghani, M. and Rehman, M. (2020) 'Effectiveness of basic training session regarding the awareness of Ebola virus disease among nurses of public tertiary care hospitals of Lahore', Journal of the Pakistan Medical Association, 70(3), pp. 477-481. doi: 10.5455/JPMA. 15677.

Saqlain, M. et al. (2020) 'Knowledge, attitude, practice and perceived barriers among healthcare workers regarding COVID-19: a cross- sectional survey from Pakistan', Journal of Hospital Infection, 105(3), pp. 419-423. doi: 10.1016/j.jhin.2020.05.007.

Srikanth Bhagavathula, A. et al. (2020) 'Novel Coronavirus (COVID-19) Knowledge and Perceptions: A Survey of Healthcare Workers', medRxiv, p. 2020.03.09.20033381. doi: 10.1101/2020.03.09.20033381.

'WHO announces COVID-19 outbreak a pandemic' (2020).

Zhong, B. L. et al. (2020) 'Knowledge, attitudes, and practices towards COVID-19 among chinese residents during the rapid rise period of the COVID-19 outbreak: A quick online cross-sectional survey', International Journal of Biological Sciences, 16(10), pp. 1745-1752. doi: 10.7150/ijbs.45221.

Zhou, W. et al. (2020) 'Effects of media reporting on mitigating spread of COVID-19 in the early phase of the outbreak', Mathematical Biosciences and Engineering, 17(3), pp. 2693-2707. doi: 10.3934/mbe.2020147. 